\title{
Neuroticism, extraversion, life events
}

\section{and depression}

\author{
The Cardiff Depression Study
}

ANNE FARMER, KATE REDMAN, TANYA HARRIS, ARSHAD MAHMOOD,
STEPHANIE SADLER, ANDREA PICKERING and PETER McGUFFIN

\author{
Background Certain personality \\ traits may mediate the relationship \\ between familiality and adversity in \\ causing depression.
}

\begin{abstract}
Aims To examine whether the neuroticism and extraversion scales of the Eysenck Personality Inventory (EPI) represent enduring traits underlying the vulnerability to respond to adversity by developing depressive episodes.
\end{abstract}

\begin{abstract}
Method A total of 108 subjects with depression and their siblings were compared with 105 healthy control subjects and their siblings. All were interviewed using the Schedules for the Clinical Assessment of Neuropsychiatry and the Life Events and Difficulties
\end{abstract} Schedule. Subjects also completed the EPI.

\section{Results Both neuroticism and extraversion were familial and correlated with mood and life event measures. There were no differences on either measure between the never-depressed siblings of probands with depression and controls. Regression analyses showed that the major influence on neuroticism was current mood.}

\section{Conclusions Neither extraversion nor neuroticism measures trait vulnerability to depression, and neuroticism scores mainly reflect symptoms of depression.}

Declaration of interest Funded by a grant from the WellcomeTrust.
The relationship between excess adverse events (Brown \& Harris, 1978) and genetic risk factors (Plomin et al, 2001) for depression could be mediated by aspects of personality, such as neuroticism or extraversion (Eysenck \& Eysenck, 1975), that also run in families. For example, neurotic traits could lead to an individual being excessively concerned about the occurrence of an adverse event (i.e. threat perceiving). Alternatively, risk-taking behaviours associated with extraversion, for example, could lead to the occurrence of excess events (hazard prone) (McGuffin et al, 1988). In this report from the Cardiff Depression Study (Farmer et al, 2000) we will examine the relationship between depression, life events and scores on the neuroticism and extraversion scales of the Eysenck Personality Inventory (EPI). We predict that both neuroticism and extraversion will be correlated with measures of depression, as well as the number of events experienced by subjects. Also, we hypothesise that neuroticism and extraversion scale scores will exhibit trait-like qualities, rather than being substantially influenced by alteration in mood-state.

\section{METHOD}

The Cardiff Depression Study has been detailed previously elsewhere (Farmer et $a l, 2000,2001)$. The method of subject selection and evaluation was as follows.

\section{Proband and sibling recruitment}

A total of 108 probands with depression (D-probands) aged 18-65 years who fulfilled ICD-10 (World Health Organization, 1993) criteria F32 and F33 and who had a sibling (D-sib) who was willing to be studied were recruited. Following regular reviews of admissions to the psychiatric services in Gwent and South Glamorgan, individuals likely to fulfil the study criteria were personally approached regarding participation. Subjects with a lifetime-ever history of psychotic or bipolar symptoms were excluded from further study, as were those subjects where it was not possible to recruit their sibling. D-probands were also recruited from two general practitioner lists in Cardiff.

Age- and gender-matched control subjects (C-probands) were recruited from patients attending Dental and Orthopaedic out-patient clinics and from among the employees of the University Hospital of Wales NHS Trust. Control probands were recruited if they had no current or past history of depression, and had a sibling (C-sib) who was willing to participate in the study. Wherever possible for both Dprobands and C-probands, the sibling nearest in age was recruited. However, if this sibling was unavailable or unwilling, the sibling next in age was asked to participate. Most interviews were conducted face to face but for $18.5 \%$ of the D-sibs and $33.3 \%$ of C-sibs telephone interviews were undertaken.

\section{Interviews and self-rating questionnaires}

All subjects were interviewed using the Schedule for the Clinical Assessment for Neuropsychiatry (SCAN; Wing et al, 1990) and the Life Events and Difficulty Schedule (LEDS; Brown \& Harris, 1978). Life events occurring over a 12-month time frame were examined using the LEDS method. An expert panel (Brown \& Harris, 1978; Farmer et al, 2000) contextually rated each subject's reported events and difficulties. For all subjects who were depressed at the time of interview, the date of onset of the current episode was carefully determined and life events recorded for the 12 months prior to that date. All remaining subjects who were not depressed at the time of interview were asked about events and difficulties occurring over the 12 months prior to interview. All subjects also completed a number of self-report questionnaires, including the EPI (Eysenck \& Eysenck, 1975) and the Beck Depression Inventory (BDI; Beck, 1978).

Information obtained at the SCAN interview was entered into the CATEGO 5 scoring program to obtain ICD-10 diagnoses and an eight-point psychopathology severity rating, the index of definition for each subject.

The Statistical Package for the Social Sciences (SPSS, version 10 for Windows) was used to create a database and undertake the statistical analyses. 


\section{RESULTS}

\section{Brief demographic details of the subject groups}

These have been described in detail elsewhere (Farmer et al, 2000, 2001). The percentage of female subjects and mean ages for each subject group were as follows: 108 D-probands, $65 \%$ female, mean age 39.78 years (s.e. $=1.03$ ); 108 D-sibs, 69\% female, mean age 38.6 years (s.e. $=1.02$ ); 105 C-probands, $74 \%$ female, mean age 36.2 years (s.e. $=1.20$ ); $105 \mathrm{C}$-sibs, 60\% female, mean age 39.10 years (s.e. $=1.22$ ). There were no significant differences between the groups for age or gender. There were also no significant differences between the D-probands and C-probands for marital status. However, only $52 \%$ of the D-probands were in paid employment, compared with $82 \%$ of C-probands.

Of the D-probands, 36 were experiencing their first episode of depression and the remaining 72 had also been depressed in the past. Nineteen of the D-sibs also reported having received past treatment for depression, and eight were depressed at the time of interview. Five of the C-sibs reported previous treatment for depression but none were depressed at the time of interview. The relative risk $(\lambda)$ for reported treatment for depression in D-sibs compared with C-sibs was 5.42 (Farmer et al, 2000).

\section{Neuroticism and extraversion scales, age and gender}

Scores on the neuroticism and extraversion scales were significantly negatively correlated with age (neuroticism: Pearson's correlation coefficient $r=-0.10, P=0.04$; extraversion: $r=-0.12, P=0.01$ ).

Male subjects scored significantly lower on neuroticism compared with female subjects, although there were no gender differences for extraversion. Mean neuroticism score for 140 male subjects was 10.88 (s.e. $=0.58$ ) and for 286 female subjects was $13.15 \quad($ s.e. $=0.40) \quad(t$-test: $t=-3.23$, d.f. $=272.89, P=0.001)$. Mean extraversion score for the male subjects was 13.26 (s.e. $=0.54)$ and for female subjects it was 12.49 (s.e. $=0.36$ ).

\section{Neuroticism and extraversion scores and present and past history of depression}

Neuroticism, extraversion and depression ratings at time of interview

Mean neuroticism and extraversion scores for the four groups of participants in the
Cardiff Depression Study are shown in Table 1. The D-probands scored significantly higher on neuroticism compared with the other three groups (analysis of variance (ANOVA): $F=94.92$, d.f. $=3,425$, $P<0.001$; Tukey B post hoc test: D-probands $>$ D-sibs $>$ C-probands, C-sibs) and significantly lower on extraversion compared with the other three groups (ANOVA: $F=25.54$, d.f. $=3,425, P<0.001$; Tukey B post hoc test: D-probands $<\mathrm{D}$-sibs $<\mathrm{C}$-probands, C-sibs).

For all four groups combined, neuroticism and extraversion scores were significantly correlated with BDI scores (neuroticism: $r=0.70, \quad P<0.001$; extraversion: $r=-0.43, P<0.001)$. When the healthy controls (C-probands) were examined separately, there was a significant positive correlation for neuroticism and BDI $(r=0.47, P<0.001)$ but not for extraversion and BDI $(r=-0.12, P=\mathrm{NS})$.

\section{Neuroticism, extraversion and past history of depression}

Nineteen of the D-sibs had had a past episode of depression but were not ill at the time of interview, whereas $81 \mathrm{D}$-sibs had never been depressed. The D-sibs who had never been depressed had a mean neuroticism score of 10.11 (s.e. $=0.69$ ), whereas those with a history of depression had a mean neuroticism score of 15.32 (s.e.=1.32). These mean differences were statistically significant ( $t$-test: $t=-3.50$, d.f. $=26.82, P=0.002)$. There were no differences between the groups for mean scores on extraversion. The D-sibs who had never been depressed had a mean extraversion score of 13.28 (s.e. $=0.77$ ), whereas D-sibs with a history of depression had a mean extraversion score of 13.11 (s.e.=1.47).

\section{Familiality of neuroticism and extraversion and scores for siblings with no history of depression}

Neuroticism and extraversion were significantly correlated across the sib pairs, for both types of proband and their siblings combined (neuroticism: $r=0.33, P<0.001$; extraversion: $r=0.24, P=0.001$ ).

A total of $81 \mathrm{D}$-sibs and $100 \mathrm{C}$-sibs reported never being depressed. Mean neuroticism score for these D-sibs was 10.11 (s.e. $=0.69$ ) and for the C-sibs it was 8.96 (s.e. $=0.53)$. These differences were not statistically significant. Mean extraversion score for these $\mathrm{D}$-sibs was
Table I Neuroticism ( $N$ ) and extraversion (E) mean scores and standard errors in probands with depression (D-probands) and their siblings (D-sibs) and in control probands (C-probands) and their siblings (C-sibs)

\begin{tabular}{lcccc}
\hline & $n$ & EPI & Mean & s.e. \\
\hline D-probands & 108 & N & $19.57^{\prime}$ & 0.35 \\
& & E & $8.86^{2}$ & 0.56 \\
D-sibs & & & & \\
& 108 & $\mathrm{~N}$ & 11.93 & 0.66 \\
C-probands & & $\mathrm{E}$ & 12.69 & 0.66 \\
& 105 & $\mathrm{~N}$ & 8.72 & 0.49 \\
& & $\mathrm{E}$ & 14.98 & 0.48 \\
C-sibs & & & & \\
& & $\mathrm{N}$ & 9.21 & 0.52 \\
& & $\mathrm{E}$ & 14.57 & 0.49 \\
\hline
\end{tabular}

I. Analysis of variance (ANOVA) for $\mathrm{N}$ scores (D-probands significantly higher scores): $F=94.92$, d.f. $=3,425$, $P<0.001$. Tukey $B$ post hoc test: $D$-probands $>D$ sibs $>$ C-probands, C-sibs.

2. ANOVA for $E$ scores (D-probands significantly lower scores): $F=25.54$, d.f. $=3,425, P<0.001$. Tukey $B$ post hoc test: D-probands $<\mathrm{D}$-sibs $<\mathrm{C}$-probands, $\mathrm{C}$-sibs.

13.28 (s.e. $=0.77$ ) and for the C-sibs it was 14.46 (s.e. $=0.51)$. These differences were not statistically significant.

\section{Life events and neuroticism and extraversion scores}

Neuroticism scores were significantly correlated with the number of severe and threatening contextually rated life events in 1 year (LEDS-rated 1 and 2 events: $r=0.22, \quad P<0.001)$. Extraversion scores were not significantly correlated with the number of severe threatening events $(r=-0.04)$ but were significantly correlated with the number of less severe events in 1 year (LEDS-rated 3 and 4 events: $r=0.11, P=0.02$ ).

\section{Multiple regression analysis}

Multiple regression analyses of data from the four subject groups were carried out first with neuroticism and then with extraversion taken as the dependent variables. Five dichotomous dummy variables were created from the following groups of subjects. A total of 93 individuals $(86 \mathrm{D}$ probands and $7 \mathrm{D}$-sibs) were experiencing a first episode of depression (DEP1st) and 73 (72 D-probands and 1 D-sib) were currently depressed and had been depressed in the past (DEPCR). Twenty-four subjects (19 D-sibs and $5 \mathrm{C}$-sibs) had a past history of treatment for depression but were well at 
the time of interview (DEPEV). The dummy variable PROSIB determined whether the subject was a proband or a sib, whereas PRODEP identified whether the subject was from a pair ascertained via a D-proband or a C-proband. The five dummy variables, plus $\mathrm{BDI}$ score (BDI), gender (GENDER), age (AGE) and the number of life events contextually rated as occurring over a 12-month period, both severe and threatening (N12C) and less severe (N34C), were entered as independent variables in a multiple regression analysis. The results are shown in Table 2. For neuroticism, all independent variables relating to present or past history of depression, age and gender have significant $\beta$ coefficients. In order of size effect, the significant $\beta$ coefficients are 0.48 for BDI, 0.21 for current and past history of depression (DEPCR), 0.15 for first episode of depression (DEP1st), 0.13 for currently well but past history of depression (DEPEV), -0.11 for age, -0.10 for being from a D-proband or a C-proband sibling pair (PRODEP) and 0.09 for gender. The remaining independent variables - numbers of severe (N12C) and less severe events $(\mathrm{N} 34 \mathrm{C})$ in 12 months and being a proband or a sibling (PROSIB) - have small and non-significant effects.

By contrast, for extraversion, only the BDI score $(\beta$ coefficient $=-0.33)$, PROSIB $(\beta$ coefficient $=0.15)$ and age $(\beta$ coefficient $=-0.11)$ are significant. The remaining independent variables have small and nonsignificant effects.

Because these analyses showed that current mental state and past history of depression were highly influential in determining both neuroticism and extraversion scores, further regression analyses were carried out on just the healthy C-probands, who had never been depressed. These results are shown in Table 3. As before, neuroticism and extraversion were taken as the dependent variables. The following independent variables were included: BDI, AGE, GENDER, N12C and N34C. As Table 3 shows that for neuroticism only BDI has a significant effect ( $\beta$ coefficient $=0.47$ ), whereas for extraversion none of the independent variables has a significant effect.

\section{DISCUSSION}

Our results show broadly similar findings to previous studies for both scales. The

Table 2 Multiple regression analysis: $\beta$ coefficients, $t$-values and significance levels for neuroticism and extraversion (all subjects)

\begin{tabular}{|c|c|c|c|c|c|c|}
\hline \multirow[t]{2}{*}{ Predictor variable } & \multicolumn{3}{|c|}{ Neuroticism } & \multicolumn{3}{|c|}{ Extraversion } \\
\hline & $\beta$ & $t$ & $P$ & $\beta$ & $t$ & $P$ \\
\hline Constant & & 6.46 & $<0.001$ & & 9.51 & $<0.001$ \\
\hline DEPIst & 0.15 & 2.99 & $<0.001$ & -0.03 & -0.4 & 0.69 \\
\hline DEPCR & 0.21 & 3.30 & $<0.00 \mathrm{I}$ & -0.12 & -1.43 & 0.15 \\
\hline DEPEV & 0.13 & 3.61 & $<0.00 \mathrm{I}$ & 0.06 & 1.28 & 0.21 \\
\hline PROSIB & 0.04 & 0.78 & 0.44 & -0.06 & -0.95 & 0.34 \\
\hline PRODEP & -0.10 & -2.10 & 0.04 & 0.13 & 2.08 & 0.04 \\
\hline BDI & 0.48 & 8.96 & $<0.00 \mathrm{I}$ & -0.31 & -4.35 & $<0.001$ \\
\hline GENDER & 0.09 & 2.99 & 0.01 & -0.02 & -0.54 & 0.59 \\
\hline AGE & -0.11 & -3.40 & 0.00 & -0.10 & -2.32 & 0.02 \\
\hline $\mathrm{NI} 2 \mathrm{C}$ & 0.01 & 0.28 & 0.78 & 0.07 & 1.58 & 0.12 \\
\hline N34C & 0.02 & 0.58 & 0.56 & 0.04 & 0.85 & 0.40 \\
\hline
\end{tabular}

DEPIst, currently depressed, no previous episode; DEPCR, currently depressed and past history of depression; DEPEV past history of depression, currently well; PROSIB, proband or sibling; PRODEP, subject from depression or control pair; BDI, Beck Depression Inventory score; GENDER, male or female; AGE, age at interview; NI2C, number of severe threatening life events in 12 months; N34C, number of less severe events in 12 months.

negative correlation of both scales with age has been noted by Kendell \& DiScipio (1968), whereas the elevated neuroticism scores in female subjects and the absence of significant differences between males and females for extraversion scores have been reported previously by Katz \& McGuffin (1987). The high positive correlation of neuroticism with various depression measures has been noted in many previous studies (Kendell \& DiScipio, 1968; Katz \& McGuffin, 1987), as has the negative correlation for extraversion scores (Saklofske et al, 1995).

The results show that both of the EPI scales are significantly correlated in sibling pairs. These findings confirm the familiality of neuroticism and extraversion scores, which have been shown in other family and genetic studies. Indeed, twin studies have confirmed heritability estimates of

Table 3 Multiple regression analysis: $\beta$ coefficients, $t$-values and significance levels for neuroticism and extraversion in healthy controls (C-probands)

\begin{tabular}{|c|c|c|c|c|c|c|}
\hline \multirow[t]{2}{*}{ Predictor variable } & \multicolumn{3}{|c|}{ Neuroticism } & \multicolumn{3}{|c|}{ Extraversion } \\
\hline & $\beta$ & $t$ & $P$ & $\beta$ & $t$ & $P$ \\
\hline Constant & & 2.01 & 0.05 & & 6.50 & $<0.001$ \\
\hline BDI & 0.47 & 5.25 & $<0.001$ & -0.09 & -0.92 & 0.36 \\
\hline AGE & -0.11 & -1.25 & 0.21 & -0.10 & -1.01 & 0.32 \\
\hline GENDER & 0.13 & 1.50 & 0.14 & -0.07 & -0.66 & 0.51 \\
\hline $\mathrm{N} / 2 \mathrm{C}$ & 0.01 & 0.16 & 0.88 & -0.03 & -0.26 & 0.79 \\
\hline N34C & 0.14 & 1.56 & 0.12 & 0.01 & 0.13 & 0.90 \\
\hline
\end{tabular}

BDI, Beck Depression Inventory score; NI2C, number of severe threatening life events in 12 months; N34C, number of less severe events in 12 months. 


\section{Relationship to life event measures}

Neuroticism scores were significantly correlated with the number of severe threatening events in the past 12 months, that is, the type of event well-recognised as being associated with the onset of depression (Brown \& Harris, 1978). Extraversion scores were not significantly correlated with these events but were significantly correlated with the less severe events. We have shown previously that scores for sensation-seeking in the Cardiff sibling pairs are significantly correlated with less severe events (Farmer et al, 2001). Consequently, high scores on extraversion as well as sensation-seeking appear to be associated with 'event proneness', but the types of event experienced pose little threat (Farmer et al, 2001).

\section{Multiple regression analyses}

Regression analyses were undertaken in order to tease apart the influence of current and past depression, life events, age and gender on neuroticism and extraversion scores, first on all subjects combined (Table 2) and then on the C-probands alone (Table 3). The C-probands were selected for mental health and, as we have noted elsewhere, the design meant that they and their siblings were likely to have been an unusually stable and agreeable group of subjects (Farmer et al, 2000).

The results show that the overwhelming influence on neuroticism scores is current depression (BDI score), although age, gender, depression in the past and being related to an individual with depression are also significant factors in determining neuroticism scores. For extraversion the major correlates of low scores are current mood and being a D-proband or D-sib, although age is also significant (see Table 2). Somewhat surprisingly, the relationship between neuroticism and BDI score remains significant when the multiple regression analysis is carried out on the C-probands alone (see Table 3), although this is not the case for extraversion scores, where there are no significant findings.

The EPI was designed to measure enduring personality traits (Eysenck \& Eysenck, 1975), although it has been acknowledged also that scores fluctuate with the mood state (Kendell \& DiScipio, 1968; Katz \& McGuffin, 1987). Furthermore, there is also general acceptance that neuroticism represents a genetically influenced trait underlying the vulnerability to

\section{CLINICAL IMPLICATIONS}

Both neuroticism and extraversion scores correlated with depression and different types of life event, and are familial.

- High extraversion scores may protect against depression.

- Neuroticism reflects subclinical or residual symptoms of depression.

\section{LIMITATIONS}

Probands with depression and control probands were not systematically ascertained.

- Control probands and siblings selected for health may have inflated differences between groups.

- Interviewers undertook both the Schedule for the Clinical Assessment of Neuropsychiatry and the Life Events and Difficulties Schedule together, so life events were not rated blind to psychopathology measures.

ANNE FARMER, FRCPsych, MRC Social Genetic and Developmental Psychiatric Research Centre, Institute of Psychiatry, London; KATE REDMAN, PhD, TANYA HARRIS, PhD, ARSHAD MAHMOOD, MRCPsych, STEPHANIE SADLER, MRCPsych, Department of Psychological Medicine, University of Wales College of Medicine, Cardiff; ANDREA PICKERING, BSc, PETER McGUFFIN, FRCPsych, MRC Social Genetic and Developmental Psychiatric Research Centre, Institute of Psychiatry, London

Correspondence: Anne Farmer, MRC Social Genetic and Developmental Psychiatric Research Centre, Institute of Psychiatry, III Denmark Hill, London SE5 8AF, UK

(First received 29 August 200I, final revision 7 March 2002, accepted 5 April 2002)

develop depression (Duggan et al, 1995). This has been largely based on the results of twin and family studies, which indicate that neuroticism is heritable and that the scores are stable over time (Santor et al, 1997). However, depressive symptoms are common in the general population and are also heritable (Kendler et al, 1986). Similarly, those recovering from depressive episodes often also retain subclinical symptoms for over time. It therefore remains a moot point as to whether, in clinically ascertained samples, neuroticism reflects vulnerability to depression or is mainly an indicator of past or present overt depressive symptoms. The results from the Cardiff Depression Study suggest that neuroticism is in large part a proxy measure for present or past depression. However, neuroticism does seem to be associated with higher rates of threatening events and, to this extent, may be associated with 'high threat perception'.

On the other hand, extraversion scores are lowered in depression and significantly associated with non-threatening rather than threatening events. The findings suggest that extraversion is associated with an eventful rather than hazard-prone lifestyle. Experiencing an excess of such events may better equip high-extraversion-scoring individuals to cope with the more severe and threatening events when they occur. Consequently, high extraversion may exert some protective effect from depression.

\section{REFERENCES}

Beck, A. T. (1978) The Beck Depression Inventory (BDI). New York: Psychological Corporation.

Brown, G. W. \& Harris, T. O. (1978) Social Origins of Depression. A Study of Psychiatric Disorder in Women (5th edn). London: Routledge.

Duggan, C., Sham, P., Lee, A., et al (1995)

Neuroticism; a vulnerability marker for depression, evidence from a family study. Journal of Affective Disorders, 35, 139-143.

Eysenck, H. J. \& Eysenck, S. B. G. (1975) Manual of the Eysenck Personality Inventory. London: Hodder \& Stoughton. 
Farmer, A., Harris, T., Redman, K., et al (2000) Cardiff Depression Study. A sib-pair study of life events and familiality in major depression. British Journal of Psychiatry, I76, 150-155.

_, Redman, K., Harris, T., et al (200I) Sensationseeking, life events and depression. The Cardiff Depression Study. British Journal of Psychiatry, $\mathbf{1 7 8}$, 549-552.

Katz, R. \& McGuffin, P. (1987) Neuroticism in familia depression. Psychological Medicine, 17, 155-161.

Kendell, R. E. \& DiScipio, W. J. (1968) Eysenck

Personality Inventory scores of patients with depressive illnesses. British Journal of Psychiatry, II4, 767-770.
Kendler, K. S., Heath, A., Martin, N. G., et al (1986) Symptoms of anxiety and depression in a volunteer twin population: the aetiological role of genetic and environmental factors. Archives of General Psychiatry, 43 213-221.

McGuffin, P., Katz, R. \& Bebbington, P. (1988) The Camberwell Collaborative Depression Study. III. Depression and adversity in the relatives of depressed probands. British Journal of Psychiatry, 152, 775-782.

Plomin, R., De Fries, J., McClearn, G., et al (200I) Behavioural Genetics (4th edn). New York: Freeman.
Saklofske, D. F., Kelly, I. W. \& Jansen, B. L. (1995) Neuroticism, depression and depression proneness. Personality and Individual Differences, 18, 27-31.

Santor, D. A., Bagby, R. M. \& Joffe, R. T. (1997) Evaluating stability and change in personality and depression. Journal of Personality and Social Psychology, 73, 1354-1362.

Wing, J. K., Babor, T., Brugha, T., et al (1990) SCAN Schedules for Clinical Assessment in Neuropsychiatry. Archives of General Psychiatry, 47, 589-593.

World Health Organization (1993) The ICD-10 Classification of Mental and Behavioural Disorders. Diagnostic Criteria for Research. Geneva: WHO. 